\title{
A Result in Best Approximation Theory for Family of Maps
}

\author{
Savita Rathee \\ Department of Mathematics, \\ Maharshi Dayanand University, \\ Rohtak (Haryana)-124001, India.
}

\author{
Reetu \\ Department of Mathematics, \\ Maharshi Dayanand University, \\ Rohtak (Haryana)-124001, India
}

\begin{abstract}
The aim of the present paper is to establish common fixed point and best approximation results for family of weakly compatible mappings which unify and generalize various known results.
\end{abstract}

\section{Keywords}

Common fixed point; Weakly Compatible maps; Best approximation.

\section{AMS Subject Classification 41A50, 47H10, 54H25, 55M20}

\section{INTRODUCTION}

The problem of best approximation began in 1853 with P. L. Chebyshev who considered the problem in the space of all real valued continuous functions defined on $[a, b]$, a closed real interval in R. However, the result given by Meinardus [11] was the fundamental result in this direction. In 1963, Meinardus [11] employed the Schauder fixed point theorem to prove a result regarding invariant approximation in Banach spaces. In 1969, Brosowski [5] obtained celebrated results and generalized the Meinardus's result. Since then a number of results have been proved following in the direction of Brosowski [5]. In 1977, Subrahmanyam [18] extended the Meinardus result to a finite dimensional subspace. In 1979, Singh [17] further improved the results of Brosowski [5] in many ways. In 1982, Hicks and Humpheries [6] generalized the results regarding invariant approximation. In the year 1988, Shahab et al. [14] extended the results of Hicks and Humpheries [6] and Singh [17] by considering a pair of mappings wherein one is linear and the other one is nonexpansive.

In 1992, Beg et al. [4] proved results on the existence of the best approximant for relatively contractive commuting mappings on convex metric spaces which also generalized the core result of Sahab et al. [14]. In 1996, Al-Thagafi [1] established some theorems on invariant approximations for commuting maps.

By introducing the concept of noncommuting maps to this area Shahzad [15], Al-Thagafi and Shahzad [2, 3], Hussain and Jungck [8], Hussain [7], Hussain and Rhoades [9], Jungck and Hussain [10], O'Regan and Hussain [12] and Pathak and Hussain [13] extended and improved the above mentioned results to noncommuting maps such as pointwise $\mathrm{R}$ subweakly commuting maps, compatible maps, $\quad C_{q^{-}}$ commuting maps and Banach operator pairs.

The aim of this paper is to extend the fixed point results of Singh and Tomar [16] for family of maps to best approximation. We also extend the best approximation result of Sumitra et al. [19] to family of mappings.

Before going to main result we need some preliminaries and results as follows:

Definition 1.1: Let $X$ be a non-empty set and $T: X \rightarrow X$ be a self map. Then $x \in X$ is a fixed point of $T$ if $T(x)=x$. We denote by $\operatorname{Fix}(\mathbf{T})$, the set of all fixed points of $\mathrm{T}$.

Definition 1.2: Let $(X, d)$ be a metric space and $T, S: X \rightarrow X$. A point $x \in X$ is called:

(1) a coincidence point of the pair $(T, S)$ if $T x=S x$,

(2) a common fixed point of the pair $(T, S)$ if $x=T x=S x$.

Definition 1.3: Let $(X, d)$ be a metric space and $M$ be a nonempty subset of $X$. Let $T, S: X \rightarrow X$. The pair $(T, S)$ is said to be weakly compatible if they commute at their coincidence points, i.e., $S T x=$ TSx whenever $\mathrm{Sx}=\mathrm{Tx}$.

Definition 1.4: Let $(X, d)$ be a metric space and $M$ be any closed subset of $X$. If there exists a $y_{0} \in M$ such that $d\left(x, y_{0}\right)=d(x, M)=\inf _{y \in M} d(x, y)$ then $y_{0}$ is called a best approximation to $x$ out of $M$. We denote by $\mathbf{P}_{\mathbf{M}}(\mathbf{x})$, the set of all best approximation to $\mathrm{x}$ out of $\mathrm{M}$.

In 2003, Singh and Tomar [16] gave the following result:

Theorem A: Let $\left\{A_{i}\right\}, \mathrm{i}=1,2, \ldots, \mathrm{S}$ and $\mathrm{T}$ be selfmaps of a metric space $(\mathrm{X}, \mathrm{d})$. If one of $\mathrm{SX}, \mathrm{TX}$ or $A_{i} \mathrm{X}$ is a complete subspace of $\mathrm{X}$ such that

(i) $A_{1} \mathrm{X} \subseteq \mathrm{TX}$ and $A_{i} \mathrm{X} \subseteq \mathrm{SX}$,

(ii)d $\left(A_{1} \mathrm{x}, A_{2} \mathrm{y}\right)<\varphi\left(M_{12}(\mathrm{x}, \mathrm{y})\right)$ whenever $M_{12}(\mathrm{x}, \mathrm{y})>0$,

(iii) $\mathrm{d}\left(A_{1} \mathrm{x}, A_{i} \mathrm{y}\right)<\varphi\left(M_{1 i}(\mathrm{x}, \mathrm{y})\right)$ whenever $M_{1 i}(\mathrm{x}, \mathrm{y}) \neq 0$.

where $M_{1 i}(\mathrm{x}, \mathrm{y})=\max \left\{\mathrm{d}(\mathrm{Sx}, \mathrm{Ty}), \mathrm{d}\left(A_{1} \mathrm{x}, \mathrm{Sx}\right), \mathrm{d}\left(A_{i} \mathrm{y}, \mathrm{Ty}\right)\right.$, $\left.\frac{\mathrm{d}\left(A_{1} x, \mathrm{~T} y\right)+\mathrm{d}\left(A_{i} y, \mathrm{~S} x\right)}{2}\right\}$ and $\varphi: R_{+} \rightarrow R_{+}$be an upper semicontinuous function such that $\varphi(t)<\mathrm{t}$ for each $\mathrm{t}>0$.

Then:

(I) $A_{1}$ and $\mathrm{S}$ have a coincidence,

(II) $A_{i}$ and $\mathrm{T}$ have a coincidence, 
(III) $A_{1}$ and $\mathrm{S}$ have a common fixed point provided that they are weakly compatible,

(IV) $A_{i}$ and $\mathrm{T}$ have a common fixed point provided that they are weakly compatible,

(V) $A_{i}, \mathrm{~S}$ and $\mathrm{T}$, for each i, have a unique common fixed point provided that (III) and (IV) both are true.

We will need the following general common fixed point result which is a consequence of Theorem A.

Theorem B: Let $\mathrm{T}$ and $\left\{A_{i}\right\}, \mathrm{i}=1,2, \ldots$, be selfmaps of a metric space $(\mathrm{X}, \mathrm{d})$. If one of $\mathrm{TX}$ or $A_{i} \mathrm{X}$ is a complete subspace of $\mathrm{X}$ such that

(i) $\cup_{i} A_{i} \mathrm{X} \subseteq \mathrm{TX}$

(ii) $\mathrm{d}\left(A_{1} \mathrm{x}, A_{i} \mathrm{y}\right)<\varphi\left(M_{1 i}(\mathrm{x}, \mathrm{y})\right)$ whenever $M_{1 i}(\mathrm{x}, \mathrm{y}) \neq 0$

where $M_{1 i}(\mathrm{x}, \mathrm{y})=\max \left\{\mathrm{d}(\mathrm{Tx}, \mathrm{Ty}), \mathrm{d}\left(A_{1} \mathrm{x}, \mathrm{Tx}\right), \mathrm{d}\left(A_{i} \mathrm{y}, \mathrm{Ty}\right)\right.$, $\left.\frac{\mathrm{d}\left(A_{1} x, \mathrm{~T} y\right)+\mathrm{d}\left(A_{i} y, \mathrm{~T} x\right)}{2}\right\}$ and $\varphi: R_{+} \rightarrow R_{+}$be an upper semicontinuous function such that $\varphi(\mathrm{t})<\mathrm{t}$ for each $\mathrm{t}>0$. If $\mathrm{T}$ is weakly compatible with each of $A_{i}$, then $A_{i}$ and $\mathrm{T}$, for each $i$, have a unique common fixed point.

\section{MAIN RESULTS}

Now, we give the main results on common fixed point and best approximation for family of weakly compatible maps satisfying generalized contractive condition in metric spaces.

Theorem 2.1: Let $\mathrm{T}$ and $\left\{A_{i}\right\}, \mathrm{i}=1,2, \ldots$, be selfmaps of a complete metric space $(\mathrm{X}, \mathrm{d})$. Suppose that $\mathrm{u} \in \mathrm{X}$ and $A_{i}$ leaves T-invariant compact subset $\mathrm{M}$ of closed subspace $\mathrm{T}(\mathrm{X})$ as invariant. For each $\mathrm{b} \in P_{M}(\mathrm{u})$, let $\mathrm{d}\left(\mathrm{x}, A_{i} \mathrm{~b}\right)<\mathrm{d}(\mathrm{x}, \mathrm{Tb})$ and $\mathrm{Tb} \in P_{M}(\mathrm{u})$. If $\mathrm{T}$ is weakly compatible with each of $A_{i}$ and satisfy $\mathrm{d}\left(A_{1} \mathrm{x}, A_{i} \mathrm{y}\right)<\varphi\left(M_{1 i}(\mathrm{x}, \mathrm{y})\right)$, whenever $M_{1 i}(\mathrm{x}, \mathrm{y}) \neq 0$, where $M_{1 i}(\mathrm{x}, \mathrm{y})=\max \left\{\mathrm{d}(\mathrm{Tx}, \mathrm{Ty}), \mathrm{d}\left(A_{1} \mathrm{x}, \mathrm{Tx}\right), \mathrm{d}\left(A_{i} \mathrm{y}, \mathrm{Ty}\right)\right.$, $\left.\frac{\mathrm{d}\left(A_{1} x, \mathrm{~T} y\right)+\mathrm{d}\left(A_{i} y, \mathrm{~T} x\right)}{2}\right\}$ for all $\mathrm{x}, \quad \mathrm{y} \in P_{M}(\mathrm{u}) \quad \mathrm{U}\{\mathrm{u}\}$. Then $P_{M}(\mathrm{u}) \cap \operatorname{Fix}(\mathrm{T}) \cap \operatorname{Fix}\left(A_{i}\right) \neq \varnothing$.

Proof: Since $M$ is a compact subset of $\mathrm{T}(\mathrm{X})$ therefore $P_{M}(\mathrm{u}) \neq \emptyset$. Now we show that $A_{i}\left(P_{M}(\mathrm{u})\right) \subseteq \mathrm{T}\left(P_{M}(\mathrm{u})\right)$ for each i.

Assume on the contrary that there exists $\mathrm{b} \in P_{M}(\mathrm{u})$ with $A_{i} \mathrm{~b} \notin \mathrm{T}\left(P_{M}(\mathrm{u})\right)$. Consider

$$
\begin{aligned}
\mathrm{d}(\mathrm{u}, \mathrm{Tb}) & =\mathrm{d}(\mathrm{u}, \mathrm{M}) \\
& \leq \mathrm{d}\left(\mathrm{u}, A_{i} \mathrm{~b}\right) \\
& <\mathrm{d}(\mathrm{u}, \mathrm{Tb}), \text { which is a contradiction. }
\end{aligned}
$$

Hence $A_{i}\left(P_{M}(\mathrm{u})\right) \subseteq \mathrm{T}\left(P_{M}(\mathrm{u})\right)$. Now $\mathrm{T}\left(P_{M}(\mathrm{u})\right)$ being closed subset of complete metric space is complete. So by Theorem $\mathrm{B}, \mathrm{T}$ and $A_{i}$, for each i, have a common fixed point in $P_{M}(\mathrm{u})$. Thus $P_{M}(\mathrm{u}) \cap \operatorname{Fix}(\mathrm{T}) \cap \operatorname{Fix}\left(A_{i}\right) \neq \emptyset$.

Theorem 2.2: Let $\mathrm{T}$ and $\left\{A_{i}\right\}, \mathrm{i}=1,2, \ldots$, be selfmaps of a complete metric space $(\mathrm{X}, \mathrm{d})$. Suppose that $\mathrm{u} \in \operatorname{Fix}(\mathrm{T}) \cap \operatorname{Fix}\left(A_{i}\right)$ for some $\mathrm{u}$ in $\mathrm{X}$ and $A_{i}$ leaves T-invariant compact subset $\mathrm{M}$ of closed subspace $\mathrm{T}(\mathrm{X})$ as invariant. If $\mathrm{T}$ is weakly compatible with each of $A_{i}$ and satisfy $\mathrm{d}\left(A_{1} \mathrm{x}, A_{i} \mathrm{y}\right)<\varphi\left(M_{1 i}(\mathrm{x}, \mathrm{y})\right)$, whenever $M_{1 i}(\mathrm{x}, \mathrm{y}) \neq 0$, where $M_{1 i}(\mathrm{x}, \mathrm{y})=\max \left\{\mathrm{d}(\mathrm{Tx}, \mathrm{Ty}), \mathrm{d}\left(A_{1} \mathrm{x}, \mathrm{Tx}\right), \mathrm{d}\left(A_{i} \mathrm{y}, \mathrm{Ty}\right)\right.$, $\left.\frac{\mathrm{d}\left(A_{1} x, \mathrm{~T} y\right)+\mathrm{d}\left(A_{i} y, \mathrm{~T} x\right)}{2}\right\} \quad$ for all $\quad \mathrm{x}, \mathrm{y} \in P_{M}(\mathrm{u}) \cup\{\mathrm{u}\}$. Then $P_{M}(\mathrm{u}) \cap \operatorname{Fix}(\mathrm{T}) \cap \operatorname{Fix}\left(A_{i}\right) \neq \emptyset$.

Proof: Since $M$ is a compact subset of $\mathrm{T}(\mathrm{X})$, therefore $P_{M}(\mathrm{u}) \neq \emptyset$. Now we show that $A_{i}\left(P_{M}(\mathrm{u})\right) \subseteq \mathrm{T}\left(P_{M}(\mathrm{u})\right)$ for each i.

Assume on the contrary that there exists $\mathrm{b} \in P_{M}(\mathrm{u})$ with $A_{i} \mathrm{~b} \notin \mathrm{T}\left(P_{M}(\mathrm{u})\right)$. Consider

$$
\begin{aligned}
\mathrm{d}(\mathrm{u}, \mathrm{Tb}) & =\mathrm{d}(\mathrm{u}, \mathrm{M}) \\
& \leq \mathrm{d}\left(\mathrm{u}, A_{i} \mathrm{~b}\right) \\
& =\mathrm{d}\left(A_{1} \mathrm{u}, A_{i} \mathrm{~b}\right) \\
& <\max \left\{\begin{array}{llll}
\mathrm{d}(\mathrm{Tu}, \quad \mathrm{Tb}), \quad \mathrm{d}\left(A_{1} u,\right. & \mathrm{Tu}), & \mathrm{d}\left(A_{i} b, \quad \mathrm{~Tb}\right), \\
& \left.\frac{\mathrm{d}\left(A_{1} u, \mathrm{~Tb}\right)+\mathrm{d}\left(A_{i} b, \mathrm{~T} u\right)}{2}\right\}
\end{array}\right.
\end{aligned}
$$

$<\mathrm{d}(\mathrm{Tb}, \mathrm{u})$, which is a contradiction.

Hence $A_{i}\left(P_{M}(\mathrm{u})\right) \subseteq \mathrm{T}\left(P_{M}(\mathrm{u})\right)$. Now $\mathrm{T}\left(P_{M}(\mathrm{u})\right)$ being closed subset of complete metric space is complete. So by Theorem $\mathrm{B}, \mathrm{T}$ and $A_{i}$, for each i, have a common fixed point in $P_{M}(\mathrm{u})$. Thus $P_{M}(\mathrm{u}) \cap \operatorname{Fix}(\mathrm{T}) \cap \operatorname{Fix}\left(A_{i}\right) \neq \emptyset$.

\section{CONCLUSION}

From the above discussion it is clear that our results generalize and extend the results on common fixed point and best approximation to family of mappings. The results on best approximation for two or more maps can be easily obtained from these results.

\section{REFERENCES}

[1] Al-Thagafi, M. A., Common fixed points and best approximation, J. Approx Theory, 85, (1996), 318-323.

[2] Al-Thagafi, M. A. and Shahzad, N., Noncommuting selfmaps and invariant approximations, Nonlinear Anal., 64, (2006), 2778-2786.

[3] Al-Thagafi, M. A. and Shahzad, N., Generalized Inonexpansive selfmaps and invariant approximations, Acta Math Sinica, 24, (2008), 867-876.

[4] Beg, I., Shahzad, N. and Iqbal, M., Fixed point theorems and best approximation in convex metric spaces, Approx. Theory Appl., 8, (1992), 97- 105.

[5] Brosowski, B., Fixpunkts"atze in der Approximations theorie, Mathematica (Cluj), 11 (34), (1969), 195-220.

[6] Hicks, T. L. and Humpheries, M. D., A note on fixed point theorems, J. Approx. Theory, 34, (1982), 221-225.

[7] Hussain, N., Common fixed points in best approximation for Banach operator pairs with Ciric Type I-contractions, J Math Anal Appl., 338, (2008), 1351-1363.

[8] Hussain, N. and Jungck, G., Common fixed point and invariant approximation results for noncommuting generalized (f, g) non-expansive maps, J Math Anal Appl., 321, (2006), 851-861.

[9] Hussain, N. and Rhoades, B. E., $c_{q}$ - commuting maps and invariant approximations, Fixed Point Theory Appl., 9, (2006). 
[10] Jungck, G. and Hussain, N., Compatible maps and invariant approximations, J Math Anal Appl., 325(2007), 1003-1012.

[11] Meinardus, G., Invarianz bei linearn Approximation, Arch. Rat. Mech. Anal., 14, (1963), 301-303.

[12] O'Regan, D. and Hussain, N., Generalized I-contractions and pointwise R-subweakly commuting maps. Acta Math Sinica, 23, (2007), 1505-1508.

[13] Pathak, H.K. and Hussain, N., Common fixed points for Banach operator pairs with applications, Nonlinear Anal., 69, (2008), 2788-2802.

[14] Sahab, S.A., Khan, M.S. and Sessa, S., A result in best approximation theory, J. Approx. Theory, 55, (1988), 349-351.

[15] Shahzad, N., Invariant approximations and R-subweakly commuting maps, J Math Anal Appl., 257, (2001), 3945 .
[16] Singh, S. L. and Tomar, A., Weaker forms of commuting maps and existence of fixed points, J. Korea Soc. Math. Educ. Ser. B: Pure Appl. Math., 10(3), (2003), 145 161.

[17] Singh, S.P., Application of a fixed point theorem to approximation theory, J. Approx. Theory, 25, (1979), 8889.

[18] Subrahmanyam, P. V., An application of a fixed point theorem to best approximations, J. Approx. Theory, 20, (1977), $165-172$.

[19] Sumitra, R., Uthariaraj, V. R. and Hemavathy, R., Common fixed point and invariant approximation theorems for mappings satisfying generalized contraction principle, Journal of Mathematics Research, 2(2), (2010), $135-140$. 